\title{
Manfaat Dan Kemudahan E-SPT Terhadap Penggunaan Fasilitas E-SPT Oleh Wajib Pajak Pribadi
}

\author{
Okti Duwi Lestari \\ Korespondensi: okti07101998@gmail.com \\ Universitas Islam Batik Surakarta
}

\begin{abstract}
Efforts to improve tax reporting and calculation, the Directorate General of Taxes provides E-SPT to facilitate taxpayers in meeting SPT reporting. This study aims to determine whether the benefits and convenience of E-SPT have a significant effect on the use of E-SPT facilities in KPP Pratama Surakarta. The population in this study were 35 individual taxpayers at Surakarta KPP Pratama. Data analysis used multiple regression analysis. Results this study shows that simultaneously the benefits and convenience have a significant effect on the use of the E-SPT facility. The benefit of this research is that it is expected to improve the quality of service to taxpayers through the application of E-SPT. Also, the benefits also have a significant effect on the use of E-SPT facilities.

Keywords: E-SPT, benefits, convenience
\end{abstract}

Abstrak
Upaya untuk meningkatkan pelaporan dan perhitungan pajak maka Direktorat Jenderal Pajak menyediakan E-SPT untuk mempermudah WP dalam memenuhi pelaporan SPT. Penelitian ini bertujuan untuk mengetahui apakah manfaat dan kemudahan E-SPT berpengaruh signifikan terhadap penggunaan fasilitas E-SPT di KPP Pratama Surakarta.Populasi dalam penelitian ini adalah sebanyak 35 orang wajib pajak orang pribadi pada KPP Pratama Surakarta.Analisis data menggunakan analisis regresi berganda.Hasil penelitian ini menunjukkan bahwa secara serentak atas manfaat dan kemudahan berpengaruh signifikan terhadap penggunaan fasilitas E-SPT. Manfaat dari penelitian ini adalah diharapkan dapat meningkatkan kualitas pelayanan kepada wajib pajak melalui penerapan E-SPT Dan secara parsial juga manfaat berpengaruh signifikan terhadap penggunaan fasilitas E-SPT, kemudahan berpengaruh signifikan terhadap penggunaan fasilitas E-SPT di KPP Pratama Surakarta.

Kata Kunci :E-SPT, manfaat, kemudahan.

\section{A. Pendahuluan}

Di zaman teknologi modern saat ini, manusia menginginkan segala sesuatu serba mudah cepat dan instan, seperti hal nya Pelaporan Surat Pemberitahuan (SPT) yang pada umumnya selama ini dilakukan dengan menyampaikan datang langsung ke Kantor Pelayanan Pajak (KPP) kini Direktorat Jenderal Pajak menciptakan inovasi baru dalam pelaporan penghitungan pajak melalui teknologi internet. Permasalahan yang terjadi di Kantor Pelayanan Pajak (KPP) selama ini adalah antrian penyampaian SPT dari wajib pajak yang memasuki jatuh tempo pelaporan dan petugas perekaman data SPT yang jumlahnya terbatas sehingga proses perekaman menjadi lambat bahkan menjadi tunggakan perekaman, dengan demikian Direktorat Jenderal Pajak meningkatkan pelayanannya melalui internet yang terhubung langsung secara on-line. 
Agar dapat membantu pelayanan dalam pelaporan dan perekaman data SPT secara cepat, tepat, dan akurat, maka Direktorat Jenderal Pajak melakukan modernisasi perpajakan salah satu penerapannya menggunakan Elektronik SPT (e-SPT).Elektronik SPT atau e-SPT adalah aplikasi (software) yang dibuat oleh Direktorat Jenderal Pajak untuk digunakan oleh Wajib Pajak untuk kemudahan dalammenyampaikan SPT.Berbeda dengan surat pemberitahuan secara manual, dengan e-SPT akan menjadi lebih mudah dan cepat. Penyampaian surat pemberitahuan secara elektronik dapat dilakukan selama 24 jam sehari dan 7 hari seminggu.

Dalam Peraturan Direktorat Jenderal Pajak Nomor: 6/PJ/2009, yang berisi Tentang Tata Cara Penyampaian Surat Pemberitahuan dalam Bentuk Elektronik dijelaskan dalam Pasal 2 no 1 bahwa "Wajib Pajak wajib menyampaikan SPT dalam bentuk elektronik (e-SPT)" Dengan diterapkannya sistem online dalam perpajakan diharapkan dapat meningkatkan kepatuhan Wajib Pajak untuk melakukan pelaporan dan pembayaran pajak.

Penelitian sebelumnya oleh Indri Lestari (2009) di KPP Bandung dengan variabel penerapan sistem E-SPT dan kualitas informas pajak.Hasilnya pelaksanaan E-SPT PPN berpengaruh baik dalam meningkatkan kepatuhan oleh PKP. Penelitian lain oleh Nora Dwi (2006) di KPP BUMN dengan variabel Manfaat aplikasi, kemudahan aplikasi dan keinginan wajib pajak memanfaatkan fasilitas e-Government. Hasilnya manfaat dan kemudahan aplikasi mempengaruhi keinginan wajib pajak memanfaatkan e-Government .

Sehingga rumusan masalah dalam penelitian ini adalah (1)Apakah manfaat E-SPT memberikan pengaruh yang signifikan terhadap penggunaan fasilitas ESPT oleh wajib pajak orang pribadi? (2)Apakah kemudahan E-SPT memberikan pengaruh yang signifikan terhadap penggunaan fasilitas E-SPT oleh wajib pajak orang pribadi? Manfaat dari penelitian adalah(1)Penelitian diharapkan dapat meningkatkan kualitas pelayanan kepada wajib pajak melalui penerapan E-SPT. (2)Diharapkan dapat meningkatkan kesadaran masyarakat dalam memenuhi kewajiban perpajakan.(3)Untuk mengetahui apakah ada hubungan penting antara pengaruh manfaat dan kemudahan aplikasi E-SPT terhadap penggunaan fasilitas E-SPT oleh wajib pajak orang pribadi.

\section{B. TINJAUAN PUSTAKA \\ Pengertian Pajak}

Pajak merupakan sarana yang digunakan oleh pemerintah untuk memperoleh dana dari rakyat yang digunakan untuk membiayai pengelolaan Negara yang berupa pembangunan fisik maupun non fisik. Untuk pembiayaan pembangunan tersebut dibutuhkan dana yang cukup besar, sebagian besar dananya berasal dari pendapatan sektor pajak (Sri Wahyuni, 2012). Menurut Undang-Undang Ketentuan Umum dan Tata Cara PerpajakanNomor 28 Tahun 2007 pasal 1 angka 1 menjelaskan bahwa pajak adalah kontribusi wajib kepada negara yang terutang oleh orang pribadi atau badan yang bersifat memaksa berdasarkan Undang-Undang, dengan tidak mendapatkan imbalan secara langsung dan digunakan untuk keperluan Negara bagi sebesar-besarnya kemakmuran rakyat.

\section{Fugsi Pajak}

Menurut Mardiasmo (2008) fungsi pajak dalam masyarakat suatu Negara terbagi dalam 2 (dua) fungsi, yaitu: 
Fungsi budgetair (sumber dana bagi pemerintah) fungsi ini bertujuan untuk memasukan penerimaan uang untuk kas Negara sebanyakbanyaknya antara lain mengisi anggaran pendapatan dan belanja Negara (APBN) sesuai dengan target penerimaan pajak yang telah ditetapkan, sehingga posisi anggaran pendapatan dan pengeluaran yang berimbang tercapai.

Fungsi regulerend (mengatur) fungsi pajak yang secara tidak langsung dapat mengatur dan menggerakan perkembangan sarana perekonomian nasional yang produktif. Adanya pertumbuhan perekonomian yang demikian maka akan dapat menumbuhkan objek pajak dan subjek pajak yang baru yang lebih banyak lagi, sehingga basis pajak lebih meningkat lagi.

\section{Wajib Pajak}

UU No. 28 tahun 2007 pasal 1 (www.pajak.go.id) menyebutkan, definisi wajib pajak adalah orang pribadi atau badan, yang meliputi pembayar pajak, pemotong pajak, dan pemungut pajak, yang mempunyai hak dan kewajiban perpajakan sesuai dengan ketentuan peraturan perundang-undangan perpajakan.

\section{Surat Pemberitahuan Secara manual (SPT)}

Pengertian Surat Pemberitahuan (SPT) menurut Undang-Undang No.16 Tahun 2009 adalah surat yang oleh Wajib Pajak digunakan untuk melaporkan penghitungan dan/atau pembayaran pajak, objek pajak dan/atau bukan objek pajak, dan/atau harta dan kewajiban sesuai dengan ketentuan peraturan perundang-undangan perpajakan.

Surat Pemberitahuan Secara Elektronik (E-SPT)

Dalam mewujudkan sistem administrasi perpajakan modern, pemerintah menyediakan aplikasi yang dapat digunakan oleh Wajib Pajak untuk melakukan pelaporan dan pembayaran SPT secara cepat, tepat dan akurat. Menurut PER Nomor 06/PJ/2009 yang dimaksud e-SPT adalah data SPT Wajib Pajak dalam bentuk elektronik yang dibuat oleh Wajib Pajak dengan menggunakan aplikasi $e$ SPT yang disediakan oleh Direktorat Jenderal Pajak.

\section{Kerangka Berpikir}

Variabel Independen Variabel Dependen

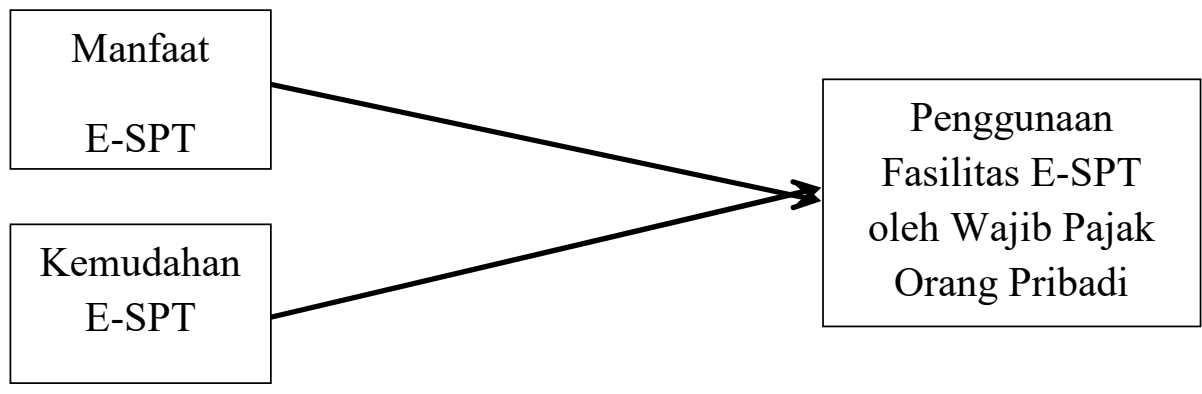

Gambar 1. Kerangka Berpikir

\section{Hipotesis}

Manfaat E-SPT memberikan pengaruh yang signifikan terhadap penggunaan fasilitas E-SPT oleh wajib pajak orang pribadi.

Dalam penelitian yang dilakukan oleh Nora (2006) diperoleh hasil bahwa manfaat E-SPT memberikan pengaruh yang signifikan penggunaan fasilitas ESPT oleh wajib pajak orang pribadi.

H1:Manfaat E-SPT memberikan pengaruh yang signifikan terhadap penggunaan fasilitas E-SPT oleh wajib pajak orang pribadi. 
Kemudahan E-SPT memberikan pengaruh yang signifikan terhadap penggunaan fasilitas E-SPT oleh wajib pajak orang pribadi.

Dalam penelitian yang dilakukan oleh Fajar Ramadhan (2010) diperoleh hasil bahwa Kemudahan E-SPT memberikan pengaruh yang signifikan terhadap penggunaan fasilitas E-SPT oleh wajib pajak orang pribadi.

H2:Kemudahan E-SPT memberikan pengaruh yang signifikan terhadap penggunaan fasilitas E-SPT oleh wajib pajak orang pribadi.

\section{METODE PENELITIAN Jenis Penelitian}

Jenis penelitian yang akan digunakan dalam penelitian ini adalah penelitian deskriptif untuk mengetahui pengaruh manfaat dan kemudahan E-SPT terhadap penggunaan fasilitas E-SPT oleh wajib pajak orang pribadi yang dilakukan di Kantor Pelayanan Pajak Pratama Surakarta.

\section{Varibel Penelitian dan Pengukurannya}

Variabel dependen dalam penelitian ini adalah Penggunaan Fasilitas ESPT oleh Wajib Pajak Pribadi.Sedangkan variable independen dalam penelitian ini adalah Manfaat E-SPT dan Kemudahan E-SPT.Pengukurannya menggunakan skalalikert.

\section{Sumber Data Dan Responden}

Data diperoleh dari Wajib Pajak Orang Pribadi (WPOP) yang telah menerapkan E-SPT yang berada di KPP Surakarta. Data tersebut berupa kuesioner yang akan diisi atau dijawab oleh Wajib Pajak Orang Pribadi yang berada di Kantor Pelayanan Pajak Pratama Surakarta.

\section{Populasi Dan Sampling}

Populasi dalam penelitian iniadalah Wajib Pajak Orang Pribadi di KPP Pratama Surakarta.Sedangkan sampel yang diambil oleh peneliti dalam penelitian ini adalah wajib pajak orang pribadi yang berada pada Kantor Pelayanan Pajak Pratama Surakarta sebanyak 35 wajib pajak. Teknik penentuan sampel dalam penelitian ini menggunakan teknik Random Sampling.

\section{Instrumen Penelitian}

Instrumen yang digunakan dalam penelitian ini adalah instrumen kuesioner untuk mengukur audit mengadopsi dari Fajar Ramadhan. Kuesioner tersebut diukur dengan memberikan skor untuk setiap jawaban responden. Adapun dalam setiap jawaban dari pertanyaan tersebut telah ditentukan skornya dengan menggunakan 5 (lima) poin skala Likert, yaitu: nilai $1=$ sangat tidak setuju, $2=$ tidak setuju, $3=$ ragu-ragu, $4=$ setuju, $5=$ sangat setuju.

\section{Metode Analisis Data}

\section{Uji Kualitas Data}

Uji Validitas

Untuk mengetahui apakah kuesioner yang digunakan valid atau tidak, maka $\mathrm{r}$ yang diperoleh ( $\mathrm{r}$ hitung) dikonsultasikan dengan ( $\mathrm{r}$ tabel) dinyatakan valid.Apabila $r$ hitung lebih besar dari $r$ tabel $(r$ hitung $>r$ tabel) maka instrumen dinyatakan valid, dan jika $r$ hitung lebih kecil dari $r$ tabel ( $\mathrm{r}$ hitung $<\mathrm{r}$ tabel) maka instrumen dinyatakan tidak valid. Uji validitas dapat diperoleh dengan bantuan program SPSS.

Uji Reabilitas 
Suatu instrumen dengan pengukuran yang menghasilkan koefisien alpha cronbach kurang dari 0.6 dipertimbangkan kurang baik.0.7 dapat diterima, dan 0.8 baik. Uji reabilitas dapat diperoleh dengan bantuan program SPSS.

\section{Uji Asumsi Klasik}

\section{Uji Multikolinearitas}

Uji multikolinearitas bertujuan untuk menguji apakah pada model regresi ditemukan adanya korelasi antar variabel independen, dengan melihat nilai inflation factor (VIF) pada model regresi dan membandingkan nilai koefisien determinasi individual $\left(\mathrm{r}^{2}\right)$ dengan niali determinasi serentak $\left(\mathrm{R}^{2}\right)$.Pada umumnya jika VIF lebih besar dari 5, maka variabel tersebut mempunyai persoalan multikolinearitas dengan variabel bebas lainnya.

\section{Uji Autokorelasi}

Untuk mengetahui ada atau tidaknya penyimpangan asusi klasik autokorelasi, dengan syarat terpenuhi adalah tidak adanya autokorelasi dalam model regresi.Uji Durbin-Waston yang sering digunakan dalam penelitian.

\section{Uji heteroskedastisitas}

Uji heteroskedastisitas bertujuan untuk menguji apakah terjadi ketidaksamaan variance dari residual satu pengamatan ke pengamatan yang lain. Jika variance dari recidual suatu pengamatan ke pengamatan lain tetap disebut Homoskedastisitas, jika berbeda disebut Heteroskedastisitas. Model regresi yang baik adalah Homoskedastisitas atau tidak terjadi Heteroskedastisitas.

\section{Uji Normalitas}

Uji normalitas bertujuan untuk mengetahui apakah data memenuhi asumsi normal atau tidak.Uji normalitas menggunakan Kolmogorov Smirnov.

\section{Uji Analisis Regresi}

Model Regresi Linear Berganda

Analisis data yang digunakan dalampenelitian ini adalah analisis regersi linearberganda dengan persamaan sebagai berikut:

dimana:

$$
\mathrm{Y}=\mathrm{a}+\mathrm{b} 1 \mathrm{X} 1+\mathrm{b} 2 \mathrm{X} 2+\mathrm{e}
$$

$$
\begin{array}{ll}
\mathrm{Y} & : \text { Penggunaan Fasilitas SPT } \\
\mathrm{a} & : \text { Konstanta } \\
\mathrm{X} 1 & : \text { Faktor Manfaat } \\
\mathrm{X} & : \text { Faktor Kemudahan } \\
\mathrm{b} 1 & : \text { Koefisien regresi variabelX1 } \\
\mathrm{b} 2 & : \text { Koefisien regresi variabelX2 } \\
\varepsilon & : \text { Error (kesalahan) } \\
\text { Uji F } &
\end{array}
$$

Jika $\mathrm{F}$ hitung lebih besar dari $\mathrm{F}$ tabel maka Ho ditolak dan $\mathrm{Ha}$ diterima. Nilai signifikan $0,000<a 0,05$ pada tingkata kepercayaan $95 \%$. Hal itu menunjukkan Ho ditolak dan Ha diterima.Sebalinya, jika F hitung lebih kecil dari F tabel, maka model tidak signifikan.

\section{Uji t}


Ho diterima apabila nilai t-hitung lebih kecil dari t-tabel dan nilai probabilitas lebih besar dari 0,05 . Ho ditolak apabila nilai t-hitung lebih beasr dari t-tabel dan nilai probabilitas lebih kecil dari 0,05 .

\section{Uji R}

Uji $R$ bertujuan untuk mengetahui nilai koefisien $r^{2}$ untuk setiap variabel yang diregresikan.Nilai $\mathrm{r}^{2}$ tersebut dibandingkan dengan nilai koefisien determinasi $\mathrm{R}^{2}$. Kriteria pengujian yaitu jika $\mathrm{r}^{2}>\mathrm{R}^{2}$ maka terjadi multikolinearitas dan jika $\mathrm{r}^{2}<\mathrm{R}^{2}$ maka tidak terjadi multikolinearitas.

\section{HASIL DAN PEMBAHASAN}

\section{Uji Kualitas Data}

\section{Uji Validitas}

Dasar pertimbangan untuk mengukur valid tidaknya kuesioner adalah dengan membandingkan antara $r$ hitung terhadap $r$ tabel. Nilai $r$ tabel untuk penelitian ini adalah $r$ tabel dengan $\mathrm{df}=(\mathrm{n}-2)=$ pada $\alpha=$ $5 \%$ yaitu 0,274. Jika $r$ hitung lebih besar dari $r$ tabel maka kuesioner dikatakan valid dan sebaliknya jika $r$ hitung lebih kecil dari $r$ tabel maka kuesioner tersebut dikatakan tidak valid sebagai instrumen penelitian. Adapun hasil uji tersebut adalah sebagai berikut :

Tabel 1. Hasil Uji Validitas

\begin{tabular}{lcccc}
\hline \multicolumn{1}{c}{ Variabel } & Item & r hitung & r tabel & Keterangan \\
\hline Manfaat (X1) & 1 & 0,527 & 0,274 & Valid \\
& 2 & 0,521 & 0,274 & Valid \\
& 3 & 0,442 & 0,274 & Valid \\
Kemudahan (X2) & 4 & 0,653 & 0,274 & Valid \\
& 5 & 0,609 & 0,274 & Valid \\
& 1 & 0,659 & 0,274 & Valid \\
Penggunaan E-SPT (Y) & 2 & 0,396 & 0,274 & Valid \\
& 3 & 0,400 & 0,274 & Valid \\
& 4 & 0,688 & 0,274 & Valid \\
& 5 & 0,522 & 0,274 & Valid \\
& 2 & 0,500 & 0,274 & Valid \\
& 3 & 0,275 & 0,274 & Valid \\
& 4 & 0,644 & 0,274 & Valid \\
& 5 & 0,449 & 0,274 & Valid \\
\end{tabular}

Sumber : data primer 2017

Hasil tersebut di atas menunjukkan bahwa butir-butir kuesioner dalam penelitian ini adalah valid hal ini ditunjukkan dengan nilai $r$ hitung pada masingmasing item lebih besar dari $\mathrm{r}$ tabel $(0,274)$, artinya seluruh butir pertanyaan dapat digunakan sebagai instrumen penelitian.

\section{Uji Reabilitas}

Suatu instrument dianggap reliabel, apabila koefisien alpha di atas 0,274 . Perhitungan uji reliabilitas dilakukan dengan program statistik.

Tabel 2. Hasil Uji Reabilitas

\begin{tabular}{lrl}
\hline Variabel & $\begin{array}{c}\text { Cronbach's } \\
\text { Alpha }\end{array}$ & Keterangan \\
\hline Manfaat (X1) & 0,776 & Reliabel
\end{tabular}




\begin{tabular}{lll} 
Kemudahan (X2) & 0,758 & Reliabel \\
Penggunaan E-SPT (Y) & 0,669 & Reliabel \\
\hline
\end{tabular}

Sumber : data primer 2017

Hasil pengujian reliabilitas terhadap seluruh item pertanyaan diperoleh nilai Cronbach Alpha lebih besar 0,6 sehingga dapat disimpulkan bahwa seluruh item pertanyaan penelitian ini telah memenuhi syarat reliabilitas.

Uji Asumsi Klasik

Uji Multikolinearitas

Berdasarkan hasil uji multikolinearitas, didapatkan hasil sebagai berikut:

Tabel 3. Hasil Uji Multikolinearitas

\begin{tabular}{cccc}
\hline Variabel & Tolerance & VIF & Ket \\
\hline X1 & 0,998 & 1,002 & Tidak ada multikolinearitas \\
X2 & 0,998 & 1,002 & Tidak ada multikolinearitas \\
\hline
\end{tabular}

Sumber: data primer 2017

Dari hasil uji multikolinearitas diatas, diperoleh nilai VIF lebih kecil dari 5 maka variabel-variabel diatas tidak mempunyai persoalan multikolinearitas dengan variabel bebas lainnya.

Uji Autokorelasi

Berdasarkan hasil uji autokorelasi, didapatkan hasil sebagai berikut:

Tabel 4. Hasil Uji Autokorelasi

\begin{tabular}{|c|c|c|c|}
\hline Model & $\mathrm{R}$ & R Square & Durbin-Watson \\
\hline 1 & 0,788 & 0,621 & 1,662 \\
\hline
\end{tabular}

Sumber: data primer 2017

Dari hasil uji autokorelasi diatas, diperoleh nilai DW $=1,662$ sehingga dapat disimpulka bahwa tidak terdapat autokorelasi karen nilai DW lebih besar dari batas atas (dU) yakni 1,583 dan kurang dari (4-dU) 4 $-1,583=2,417$.

Uji Heteroskedastisitas

Berdasarkan hasil uji heteroskedastisitas, didapatkan hasil sebagai berikut:

Tabel 6. Hasil Uji Heteroskedastisitas

\begin{tabular}{lcc}
\multicolumn{1}{c}{ Variabel } & $\mathrm{t}$ & $\mathrm{Sig}$ \\
\hline Manfaat & 0,682 & 0,499 \\
Kemudahan & $-0,387$ & 0,701 \\
\hline
\end{tabular}

Sumber: data primer 2017

Dari hasil uji heteroskedastisitas, nilai signifikansi yang diperoleh lebih besar dari 0,05 (Sig. $>0,05)$ jadi kedua variabel tidak ada gejala heteroskedastisitas.

Uji Normalitas

Berdasarkan hasil uji normalitas, didapatkan hasil sebagai berikut:

\begin{tabular}{lr}
\multicolumn{2}{c}{ Tabel 7. Hasil Uji Normalitas } \\
\hline Variabel & Asymp Sig \\
\hline Manfaat & 0,675 \\
Kemudahan & 0,084 \\
Penggunaan ESPT & 0,308 \\
\hline
\end{tabular}

Sumber: data primer 2017 
Dari tabel diatas dapat dilihat bahwa signifikansi (Asymp Sig) lebih besar dari 0,05 (Asymp Sig. > 0,05) maka Ho diterima. Jadi dapat disimpulkan bahwa distribusi manfaat, kemudahan, dan penggunaan ESPT normal.

\section{Uji Analisis Regresi}

\section{Uji Model Regresi Berganda}

Pengujian Pertama

Berdasarkan hasil ujji model regresi berganda, didapatkan hasil sebagai berikut:

\begin{tabular}{lcc}
\multicolumn{3}{c}{ Tabel 8. Hasil Uji Regresi Berganda } \\
\hline \multicolumn{1}{c}{ Variabel } & $\mathrm{t}$ & Sig \\
\hline (Contsant) & 2,529 & 0,016 \\
Manfaat & 7,232 & 0,000 \\
Kemudahan & $-0,704$ & 0,486 \\
\hline Sumber: data primer 2017 &
\end{tabular}

Data diatas menunjukkan bahwa nilai sig untuk variabel kemudahan lebih besar dari 0,05, maka hipotesis ditolak artinya variabel kemudahan tidak berpengaruh signifikan terhadap penggunaan fasilitas ESPT. Variabel manfaat memiliki nilai sig lebih kecil dari 0,05 maka hipotesis diterima artinya variabel manfaat berpengaruh terhadap penggunaan fasilitas E-SPT.

Pengujian Kedua 
Tabel 9. ANOVA

\begin{tabular}{llcc}
\hline Model & F & Sig. \\
\hline 1 & Regression & 26,216 & 0,000 \\
& Residual & & \\
\hline & Total & &
\end{tabular}

a. Predictors: (Constant), Kemudahan, Manfaat

b. Dependent Variabel: PFS

Sumber: data primer 2017

Berdasarkan data diatas, dapat disimpulkan bahwa nilai sig

Uji F didapat sebesar 0,000 maka hipotesis diterima.

Berdasarkan hasil uji F, didapatkan hasil sebagai berikut:

Tabel 10. Hail Uji F

ANOVA Table

\begin{tabular}{|c|c|c|c|c|c|c|}
\hline & & & $\mathrm{df}$ & $\begin{array}{c}\text { Mean } \\
\text { Square }\end{array}$ & $F$ & Sig \\
\hline \multirow{5}{*}{$\begin{array}{l}\text { PFS * } \\
\text { Manfaat }\end{array}$} & \multirow{3}{*}{$\begin{array}{l}\text { Between } \\
\text { Groups }\end{array}$} & \multirow{5}{*}{$\begin{array}{l}\text { (Combined) } \\
\text { Linearity } \\
\text { Deviation from } \\
\text { Linearity }\end{array}$} & 12 & 22,767 & 4,837 & 0,001 \\
\hline & & & 1 & 231,745 & 49,244 & 0,000 \\
\hline & & & 11 & 3,769 & 0,8 & 0,638 \\
\hline & Within Groups & & 22 & 4,706 & & \\
\hline & Total & & 34 & & & \\
\hline
\end{tabular}

Sumber: data primer 2017

Dari tabel diatas dapat dilihat nilai $\mathrm{F}$ hitung yaitu 4,837 sedangkan nilai $\mathrm{F}$ tabel 2,23 dengan taraf signifikan 0,05 . Karena $\mathrm{F}$ hitung lebih besar dari $\mathrm{F}$ tabel maka Ho ditolak dan Ha diterima. Terlihat dari tabel ANOVA bahwa $\mathrm{F}$ hitung $=4,837$ yang mana lebih besar dari nilai $\mathrm{F}$ tabel 2,23 diperkuat dengan nilai $\rho=0,001$ lebih kecil dari nilai kritik $\alpha=0,05$. Sehingga dapat disimpulkan bahwa kita dapat menolak Ho, dan yang artinya terdapat perbedaan.

Uji t

Berdasarkan hasil uji t, didapatkan hasil sebagai berikut:

\begin{tabular}{lccc}
\multicolumn{4}{c}{ Tabel 11. Hasil Uji t } \\
\hline Manfaat & $\mathrm{t}$ & $\mathrm{df}$ & Sig. (2-tailed) \\
Kemudahan & 0,501 & 34 & 0,619 \\
Penggunaan E-SPT & 1,551 & 34 & 0,13 \\
\hline
\end{tabular}

Sumber: data primer 2017

Berdasarkan perbandingan antara t-hitung dengan t-tabel, didapat variabel manfaat, kemudahan, penggunaan E-SPT melebihi t-tabel yaitu 2,032 maka Ho diterima. Dan berdasarkan nilai probitabilitas (sig.) lebih besar dari 0,05 , maka Ho dterima, berarti bahwa rata-rata variabel tidak kurang dari 3,00 .

\section{Uji R}

Berdasarkan hasil uji R, didapatkan hasil sebagai berikut: 
Tabel. Hasil Uji R

\begin{tabular}{lcc}
\hline Variabel Dependen & Variabel Independen & Nilai $r$ square $\left(\mathrm{r}^{2}\right)$ \\
\hline Manfaat & Kemudahan & 0,215 \\
Nilai $\mathrm{R}^{2}$ & 1,000 & \\
\hline
\end{tabular}

Sumber: data primer 2017

Dari tabel diatas dapat diketahui bahwa nilai koefisien $r^{2} y a n g$ diperoleh bernilai lebih kecil dari pada nilai koefisien determinasi $\left(\mathrm{R}^{2}\right)$.Dengan demikian dapat disimpulkan bahwa tidak terjadi masalah pada model regresi.

\section{E. PENUTUP}

\section{Kesimpulan}

Berdasarkan hasil uji t diperoleh t-hitung dengan t-tabel, didapat variabel manfaat dan kemudahan melebihi t-tabel yaitu 2,032 maka Ho diterima. Dan berdasarkan nilai probitabilitas (sig.) lebih besar dari 0,05, maka Ho dterima, berarti bahwa rata-rata variabel tidak kurang dari 3,00. Kondisi tersebut menunjukkan bahwa variabel manfaat dan kemudahan memudahkan penggunaan fasilitas E-SPT. Berdasarkan hasil pengujian secara simultan, maka dapat diketahui bahwa $\mathrm{F}$ hitung penggunaan fasilitas E-SPTlebih besar dari $\mathrm{F}$ tabel $(2,23)$ sehingga Ho ditolak dan Ha diterima yang berarti secara serempak ada pengaruh yang signifikan dari variabel-variabel independen dengan variabel dependen/terikat.

Saran

Untuk mengoptimalkan hasil dari penelitian ini, maka diharapkan mengenai masalah yang bisa dapat menambah variabel-variabel lain yang dipandang relevan dan lebih mendalam lagi pembahasannya, selain itu apabila memakai kuesioner sebaiknya dipandu ditambah dengan wawancara langsung tiap wajib pajak yang diteliti sehingga kuesioner nantinya dapat terisi dengan baik. Berikut Keterbatasan dari penelitian ini adalah kurangnya pengetahuan aturan perpajakan oleh wajib pajak

\section{DAFTAR PUSTAKA}

Burton, Richard dan Wirawan B Ilyas.2008. Hukum Pajak. Edisi Empat. Jakarta: Salemba Empat.

Mardiasmo.2008. Perpajakan. Edisi Revisi, Yogyakarta: Andi Publisher.

Nora, Dwi.2006.Pengaruh manfaat dan kemudahan aplikasi terhadap keinginan WP untuk memanfaatkan fasilitas e-Government.Jakarta: STAN.

Pandiangan, Liberti. 2008.Modernisasi dan Reformasi Pelayanan Perpajakan Berdasarkan UU Terbaru.Jakarta: PT Elex Media Komputindo.

Peraturan Direktur Jenderal Pajak Nomor 6/PJ/2009. Tentang Tata Cara Penyampaian Surat Pemberitahuan Dalam Bentuk Elektronik, (online).(Diakses dari www.pajak.go.id 23 Juli 2010).

Resmi, Siti.2007.Perpajakan: Teori dan Kasus 1. Edisi Keempat. Jakarta: Salemba Empat.

Undang-Undang Republik Indonesia Nomor 28 Tahun 2007. Tentang Ketentuan Umum Dan Tata Cara Perpajakan.(online).(Diakses dari www.pajak.go.id 23 juli 2010). 
Utomo, L. P. (2015). Pengaruh Postur Motivasi Atas Cara Pandang Wajib Pajak Kepada Fiskus Terhadap Kepatuhan Pembayaran Pajak Orang

Pribadi. Eksis: Jurnal Riset Ekonomi dan Bisnis, 10(2).

Purbowati, R., Purbowati, R. F. L., \& Lestari, R. F. (2018). Analisis Tingkat

Pertumbuhan Wajib Pajak Orang Pribadi Dan Penerimaan Pajak

Penghasilan Setelah Ditetapkannya Peraturan Menteri Keuangan Nomor

101/PMK. 010/2016 Tentang Penyesuaian Besarnya Penghasilan Tidak

Kena Pajak (Study Pada KPP Pratama Sidoarjo Barat). JAD: Jurnal Riset

Akuntansi \& Keuangan Dewantara, 1(2), 77-90.

Waluyo.2008.Akuntansi Pajak. Edisi ketiga.Jakarta: Salemba Empat.

Wibowo, Arief.2006.Kajian Tentang Perilaku Pengguna Sistem Informasi

Dengan Pendekatan Technology Acceptance Model (TAM). Jakarta: Jurnal

Universitas Budi Luhur. 